\title{
Limitation and Value of Using the Adenoma Detection Rate for Colonoscopy Quality Assurance
}

\author{
Jun Hur, Moo-Jun Baek ${ }^{1}$ \\ Depratment of Surgery, Yeil Hospital, Cheonan; ${ }^{1}$ Department of Surgery, Soonchunhyang University Cheonan Hospital, Cheonan, Korea
}

\section{See Article on Page 93-98}

The adenoma detection rate (ADR) can serve as a standard for managing the quality of colonoscopy. Therefore, each country has prepared criteria for determining that rate. According to the OMED (World Organisation of Digestive Endoscopy) in 2009, as a qualitative index of colonoscopy, the values of the ADR for males and females need to be more than $25 \%$ and $15 \%$, respectively [1].

The ADR, which requires a biopsy, can be replaced by the polyp detection rate (PDR) or the polyps-missed rate (PMR). However, the PDR and the PMR have disadvantages. For the right colon, the ADR and the PDR are not significantly different, but for the sigmoid colon and the rectum, they are different due to an increased number of hyperplastic polyps. Moreover, the PMR requires repeated checks for the same patient [2].

The ADR is affected by various factors, especially age: the lower the $\mathrm{ADR}$ is, the younger the subjects are. As a result, a proposal was recently made that the ADR be applied to patients older than 50 years of age. In the present study [3], age, body mass index, and smoking were factors associated with increased numbers of adenomas in the patients. In addition, prolonged observation time, observations during repeated insertions, changes in both the air volume and the position during observation, the use of a pigmented endoscope, and the use of a high-resolution electronic endoscope were factors associated with an increased ADR [4].

The effect of the quality of bowel preparation on the ADR has been reported to vary according to the researcher. However, because bowel preparation has a clear effect on the time of entry, the

Correspondence to: Moo-Jun Baek, M.D.

Department of Surgery, Soonchunhyang University Cheonan Hospital,

31 Suncheonhyang 6-gil, Dongnam-gu, Cheonan 31151, Korea

Tel: +82-41-570-3633, Fax: +82-41-571-0129

E-mail:ssurge@schmc.ac.kr

(c) 2017 The Korean Society of Coloproctology

This is an open-access article distributed under the terms of the Creative Commons Attribution NonCommercial License (http://creativecommons.org/licenses/by-nc/4.0) which permits unrestricted noncommercial use, distribution, and reproduction in any medium, provided the original work is properly cited. duration of the procedure, and the discomfort of the patient during the procedure, efforts to improve the quality of bowel preparation, which may be affected by changing the split-dose interval or by using new drugs, have been and are being studied [5].

In conclusion, what is important is that the adenoma detection rate can be affected by various characteristics of the patients and by the conditions related to the medical procedures. Therefore, the adenoma detection rate should be the minimum criterion for managing the quality of colonoscopy.

\section{CONFLICT OF INTEREST}

No potential conflict of interest relevant to this article was reported.

\section{REFERENCES}

1. Joint Advisory Group on Gastrointestinal Endoscopy (JAG). The Global Rating Scale [Internet]. London: Joint Advisory Group; [cited 2009 Nov 6]. Available form: http://www.grs.nhs.uk/.

2. Francis DL, Rodriguez-Correa DT, Buchner A, Harewood GC, Wallace M. Application of a conversion factor to estimate the adenoma detection rate from the polyp detection rate. Gastrointest Endosc 2011;73:493-7.

3. Park JH, Kim SJ, Hyun JH, Han KS, Kim BC, Hong CW, et al. Correlation between bowel preparation and the adenoma detection rate in screening colonoscopy. Ann Coloproctol 2017;33:93-8.

4. Shin SJ. New colonoscopy devices to improve colon neoplasm detection. Korean J Gastroenterol 2016;68:293-6.

5. Gurudu SR, Ramirez FC, Harrison ME, Leighton JA, Crowell MD. Increased adenoma detection rate with system-wide implementation of a split-dose preparation for colonoscopy. Gastrointest Endosc 2012;76:603-8.e1. 